\title{
BMJ Open Expanding access to non-communicable disease care in rural Malawi: outcomes from a retrospective cohort in an integrated NCD-HIV model
}

\author{
Emily B Wroe (D) , ${ }^{1,2}$ Noel Kalanga, ${ }^{3}$ Elizabeth L Dunbar, ${ }^{1}$ Lawrence Nazimera, ${ }^{4}$ \\ Natalie F Price, ${ }^{5}$ Adarsh Shah, ${ }^{5}$ Luckson Dullie, ${ }^{1}$ Bright Mailosi, ${ }^{1}$ Grant Gonani, ${ }^{4}$ \\ Enoch P L Ndarama, ${ }^{4}$ George C Talama, ${ }^{1}$ Gene Bukhman, ${ }^{2}$ Lila Kerr, ${ }^{1}$ \\ Emilia Connolly, ${ }^{1}$ Chiyembekezo Kachimanga ${ }^{1}$
}

To cite: Wroe EB, Kalanga N, Dunbar EL, et al. Expanding access to non-communicable disease care in rural Malawi: outcomes from a retrospective cohort in an integrated NCD-HIV model. BMJ Open 2020;10:e036836. doi:10.1136/ bmjopen-2020-036836

- Prepublication history for this paper is available online. To view these files, please visit the journal online (http://dx.doi. org/10.1136/bmjopen-2020036836).

Received 07 January 2020 Revised 25 September 2020 Accepted 03 October 2020

\section{Check for updates}

\section{Author(s) (or their} employer(s)) 2020. Re-use permitted under CC BY-NC. No commercial re-use. See rights and permissions. Published by BMJ.

${ }^{1}$ Partners In Health, Neno, Malawi

${ }^{2}$ Division of Global Health Equity, Brigham and Women's Hospital, Boston, Massachusetts, USA

${ }^{3}$ Department of Health Systems and Policy, College of Medicine, Blantyre, Malawi

${ }^{4}$ Ministry of Health, Neno District Health Office, Ministry of Health, Neno, Malawi

${ }^{5}$ Partners In Health, Boston, Massachusetts, USA

Correspondence to

Dr Emily B Wroe;

emwroe@gmail.com

\section{ABSTRACT}

Objectives Non-communicable diseases (NCDs) account for one-third of disability-adjusted life years in Malawi, and access to care is exceptionally limited. Integrated services with HIV are widely recommended, but few examples exist globally. We report descriptive outcomes from an Integrated Chronic Care Clinic (IC3).

Design This is a retrospective cohort study.

Setting The study includes an HIV-NCD clinic across 14 primary care facilities in the rural district of Neno, Malawi.

Participants All new patients, including 6233 HIV-NCD diagnoses, enrolled between January 2015 and December 2017 were included. This included 3334 patients with HIV (59.7\% women) and 2990 patients with NCD $(67.3 \%$ women), 10\% overall under age 15 years.

Interventions Patients were seen at their nearest health centre, with a hospital team visiting routinely to reinforce staffing. Data were collected on paper forms and entered into an electronic medical record.

Primary and secondary outcome measures Routine clinical measurements are reported at 1-year postenrolment for patients with more than one visit. One-year retention is reported by diagnosis.

Results NCD diagnoses were 1693 hypertension, 668 asthma, 486 epilepsy, 149 diabetes and 109 severe mental illness. By December 2018, 8.3\% of patients with NCD over 15 years were also on HIV treatment. One-year retention was $85 \%$ for HIV and $72 \%$ for NCDs, with default in $8.4 \%$ and $25.5 \%$ and deaths in $4.0 \%$ and $1.4 \%$, respectively. Clinical outcomes showed statistically significant improvement for hypertension, diabetes, asthma and epilepsy. Of the $1807(80 \%)$ of patients with HIV with viral load results, $85 \%$ had undetectable viral load.

Conclusions The IC3 model, built on an HIV platform, facilitated rapid decentralisation and access to NCD services in rural Malawi. Clinical outcomes and retention in care are favourable, suggesting that integration of chronic disease care at the primary care level poses a way forward for the large dual burden of HIV and chronic NCDs.

\section{Strengths and limitations of this study}

- There is a large body of literature recommending integrated HIV-non-communicable disease (NCD) care, but extremely few real world examples exist. Those that do exist are largely examples of NCD care limited to people living with HIV. This work provides enrolment and clinical outcomes data for a fully integrated HIV-NCD primary care clinic, providing care for all-comers with chronic disease in rural Malawi.

- This study provides one of the first examples of comprehensive primary care for NCDs in rural Malawi.

- This work's major limitation is that is an observational cohort using routinely collected clinical data, limiting the ability to evaluate all relevant clinical measures we would ideally include as well as isolate certain components of the intervention.

\section{INTRODUCTION}

Globally, the burden of non-communicable diseases (NCDs) is growing every year, and is the leading cause of death and disability, accounting for $70 \%$ of mortality. ${ }^{1}$ In Africa, infectious diseases such as HIV, malaria and tuberculosis (TB) have long been significant causes of morbidity, however NCDs are quickly overtaking these infectious diseases, and are predicted to become the most common cause of death by $2030 .{ }^{23}$ While the 2011 United Nations High Level meeting set out plans to combat this growing burden, the response has yet to fully meet this need. ${ }^{4}$ For instance, the disability-adjusted life year (DALY) burden from NCDs is estimated to be $37 \%$ in low-income countries, but development assistance allocated to NCDs was estimated to be just $1.3 \%$ in $2015 .^{5}$ In Malawi, a similar pattern emerges: the non-communicable disease and injury DALY burden is estimated to be $31 \%$ of total DALYs, yet for the 2015-2016 fiscal year, 
only $0.1 \%$ of targeted programmatic funding was designated to these conditions. ${ }^{67}$

In Malawi, a high proportion of this burden falls on patients under 40 years, and the Ministry of Health $(\mathrm{MOH})$ is increasingly recognising the importance of care delivery systems for NCDs. ${ }^{68}$ Estimates of conditionspecific prevalence estimate hypertension rates between $14 \%-16 \%$ for urban adults and $13 \%-14 \%$ for rural adults. ${ }^{9}$ Diabetes occurs in up to $5.6 \%$ of adults, with a cohort study of urban and rural finding 3\% of urban adults and $2 \%$ of rural adults presenting with diabetes. ${ }^{9}{ }^{10}$ Asthma affects approximately $5.1 \%$ of adults, and mental illness is common in Malawi, with the prevalence of common mental disorders in primary care settings suspected to be around 20\%. ${ }^{11}$ Access to care, particularly in the rural districts, is limited: for example, less than half of the health centres were equipped with the country's firstline anti-hypertensive in $2014 .{ }^{12}$ While care is available at central hospitals in large cities, $83 \%$ of the country lives in rural areas. ${ }^{13}$ In rural health facilities, studies have found that there is a basic lack of health commodities available to screen for and treat type 1 and 2 diabetes. ${ }^{814}{ }^{15}$ Studies have also suggested that low care and utilisation rates may be due to limited diagnosis as well as limited continuity of care. ${ }^{1516}$

Successful implementation of programmes to address chronic diseases is not a new concept in Malawi. Having suffered from a high HIV burden for many years, Malawi has implemented a strong HIV programme with care decentralised throughout the country, overseen by a strong central monitoring system. ${ }^{17}$ From 2010 to 2016, the HIV prevalence among persons 15-49 years old dropped from $10.6 \%$ to $8.8 \% .^{18}$ An estimated $72.7 \%$ of people living with HIV and AIDS knew their status in 2016, with $90.8 \%$ of those on treatment virally suppressed. ${ }^{19}$ The $\mathrm{MOH}$ has also become a leader in progressive antiretroviral therapy programmes, such as Option $\mathrm{B}+$ and universal treatment. ${ }^{20-22}$

Given this ongoing success in treating chronic infectious disease as well as the resources invested in these programmes, and Malawi's growing burden of chronic NCDs, integrated care for chronic diseases is an attractive solution. Applying lessons from HIV care delivery to NCDs is well described, and an integrated approach is increasingly recognised as a possible delivery model, particularly for primary care, with much of the literature focused on calling for various integrated approaches. ${ }^{23-25}$ 25-29 29

There exist many examples of combining HIV with other clinical programmes and into primary care; however, much of the early work in HIV-NCD integrated chronic care focuses primarily on screening and treating NCDs within HIV cohorts exclusively. ${ }^{30-38}$ Fully integrated HIV and NCD care is put forward as a model by several authors, but examples of fully integrated HIVNCD clinics, serving patients with and without HIV, are limited..$^{29} 3039$ Practical experience and implementation research is needed to assess the feasibility and outcomes of fully integrated HIV-NCD care. ${ }^{25}$
Situated in southwest Malawi, the rural district of Neno was formed in 2003 and did not have a hospital until 2007. HIV care was fully decentralised from 2 hospitals in Neno to 11 primary health centres by 2011 through a long-term partnership between the international nonprofit Partners In Health (PIH) and the $\mathrm{MOH}$, with a comprehensive approach featuring community health workers (CHWs), nutrition and cash transfer support for most vulnerable patients. ${ }^{40}{ }^{41}$ Neno District is consistently achieving significantly higher HIV retention and survival rates than any other district in the country. ${ }^{41}$ Leveraging this experience, in 2015, PIH and the $\mathrm{MOH}$ launched the Integrated Chronic Care Clinic (IC3) in Neno. At the two hospitals, IC3 replaced an earlier clinic for NCDs, modelled off PIH's partnership with the government of Rwanda. ${ }^{42-44}$ At the time, the NCD clinic at the two hospitals was experiencing high rates of patient default, rotating staff, and a lack of streamlined monitoring and evaluation and supply chain systems. The clinics used the HIV platform of care to include treatment for any chronic illness including hypertension, diabetes, asthma, epilepsy and mental illness regardless of a patient's HIV status. Through utilisation of the existing HIV platform, we were able to maximise staff, clinic space and overall efficiency and resources. ${ }^{45}$ In 2015, IC3 rapidly decentralised integrated HIV-NCD primary care to the existing 2 hospitals and 11 health centres in the district, and later to a newly opened 12th health centre in mid-2016.

While integrating care makes sense in resource-poor settings with high infectious and NCD burdens, the evidence base surrounding how best to prevent and manage NCDs, or integrate NCD care, in sub-Saharan Africa is severely lacking. ${ }^{26} 2746$ This paper therefore seeks to describe our clinical outcomes after integrating NCD and HIV care into one system for all-comers with a chronic disease in Neno District, Malawi. ${ }^{45}$

\section{METHODS}

\section{Setting and population}

Neno District is a district with population of 165000 in 2017, situated in the southwest zone in Malawi. ${ }^{47}$ An extremely rural setting, the majority of the population relies on subsistence agriculture, with only $4.5 \%$ of the population with electricity. ${ }^{48}$ Since 2007 PIH has partnered with the $\mathrm{MOH}$ in Neno to strengthen health services. In 2011, the Chronic Care Clinic (CCC) began enrolling patients with NCDs at Neno District Hospital, and in 2013 NCD services opened at Lisungwi Community Hospital. In early 2015, CCC was combined with the HIV programme to form IC3, and decentralised to the 11 primary health centres across the district ${ }^{45}$ (figure 1 ).

\section{IC3 program design}

The clinic-treated patients with one or more of any of the following conditions: HIV, hypertension, epilepsy, asthma, diabetes and mental illness. Patients were referred to IC3 from several settings including inpatient 
NCD and HIV Patients in Neno District Malawi in 2014 and 2018 2014

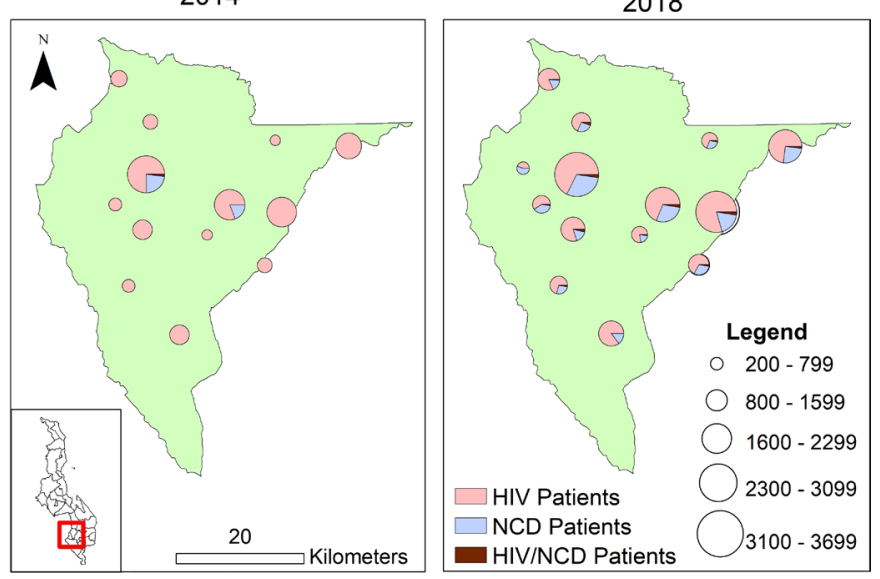

Figure 1 NCD and HIV diagnoses in Neno District over time. NCD, non-communicable disease.

wards, outpatient clinics and community-screening events. The latter were held in remote parts of the district, with participants receiving age-appropriate and genderappropriate screening for hypertension, diabetes, HIV, TB and malnutrition. Those with high blood pressure or high blood sugar were referred to their nearest facility for IC3 staff to confirm diagnosis and enrol them into care. In order to ensure the sickest patients were found early and treated, and to avoid clinic overcrowding, the referral threshold for blood pressure was systolic blood pressure $(\mathrm{SBP}) \geq 160$ and/or diastolic blood pressure $(\mathrm{DBP})>110$. Cut-off for blood sugar for referral was fasting $\geq 126 \mathrm{mg}$ / $\mathrm{dL}$ and random $\geq 200 \mathrm{mg} / \mathrm{dL} .{ }^{49}$ For mental health conditions, patients were referred from inpatient and outpatient clinics and assessed and diagnosed on admission to IC3. Once the diagnosis of mental health was confirmed, patients received both psychotherapy and pharmacotherapy at clinic visits. Mental illnesses included in the cohort are: schizophrenia, mood and anxiety disorders, schizoaffective disorder, psychosis, organic mental disorder, and alcohol and drug use-related mental disorders. Patients with a pre-existing NCD diagnosis and on medications were automatically enrolled. Patients were diagnosed using predefined NCD protocols, set by the IC3 team and HIV protocols from central $\mathrm{MOH}^{50}$

Patients enrolled in IC3 were seen at the health facility nearest to their home at regular intervals. Patients with a complex diagnosis or those starting care had a scheduled visit every month, while most other patients visited every 3 months. The clinic was staffed by clinical officers, nurses, and support staff employed both by PIH and MOH. Supervision and mentorship were performed by several physicians within the district, also employed both by MOH and PIH. Hospital-based staff would travel out to the health centres 3 or 4 days a week to conduct IC3 with health center-based counterparts. This was a solution for staffing shortages-given high volumes of maternal child health and other acute needs at primary health centres, these facilities were not equipped to handle the large influx of patients with HIV and NCDs. This system, of hospital staff travelling to support health center-based staff, had been in place for Neno's HIV care for several years. ${ }^{40}$ The HIV programme, well described elsewhere, was characterised by a strong community footprint with a network of over 900 CHWs who received a monthly stipend to assist patients with adherence, perform missed visit tracking and provide social support to especially vulnerable patients in the form of cash transfers. ${ }^{41}$ These principles were applied to IC3, with the CHW network undergoing a gradual transformation in 2017 and 2018 so that all patients with NCD were eventually assigned a CHW. $^{51}$

\section{Data collection and analysis}

This is a retrospective cohort comprised of all patients newly enrolled in IC3 at any facility in Neno District in the 36-month period between January 2015 and December 2017. Data were collected at enrolment and at routine clinical visits by clinical staff on paper forms also called master cards, which were approved and standardised by the national MOH. Data from the master cards were then regularly entered into an OpenMRS electronic medical record (EMR) system by data clerks. EMR data were extracted and used in this analysis.

Baseline demographics and clinical characteristics specific to each disease are reported using descriptive statistics. Key indicators for each condition were chosen based on available routine clinical measurements that were taken each visit based on MOH protocols, which include: blood pressure for patients with hypertension, random or fasting fingerstick for patients with diabetes, asthma severity for patients with asthma and number of monthly seizures for patients with epilepsy. Routine clinical measurements for patients with mental health illness were not available as part of this analysis. Clinical outcomes are reported at 1-year post-enrolment to the clinic for the 36-month period for all patients with more than one visit. The 1-year values were included in this analysis if it was within 3 months of the patients' 1-year anniversary. Patients were defined as default if they were still missing from clinic more than 8 weeks past their missed appointment, which is consistent with the national definition for default to care for patients with HIV. One-year survival is also reported as patients known to be alive and retained in care 12 months after their enrolment date. SDs are reported for averages for clinical outcomes such as blood pressure or blood sugar, and statistical significance for comparisons between baseline and 1 year were computed using one-sided paired t-tests for continuous values and McNemar's $X^{2}$ test for proportions. Data were analysed using Stata V.14.2 statistical software. ${ }^{52}$

\section{Patient and public involvement}

The $\mathrm{MOH}$ and Neno District Executive Council (DEC) were involved at the conception of the clinic programme design and responsible for approval for the clinic to enrol patients. The clinical services were implemented 


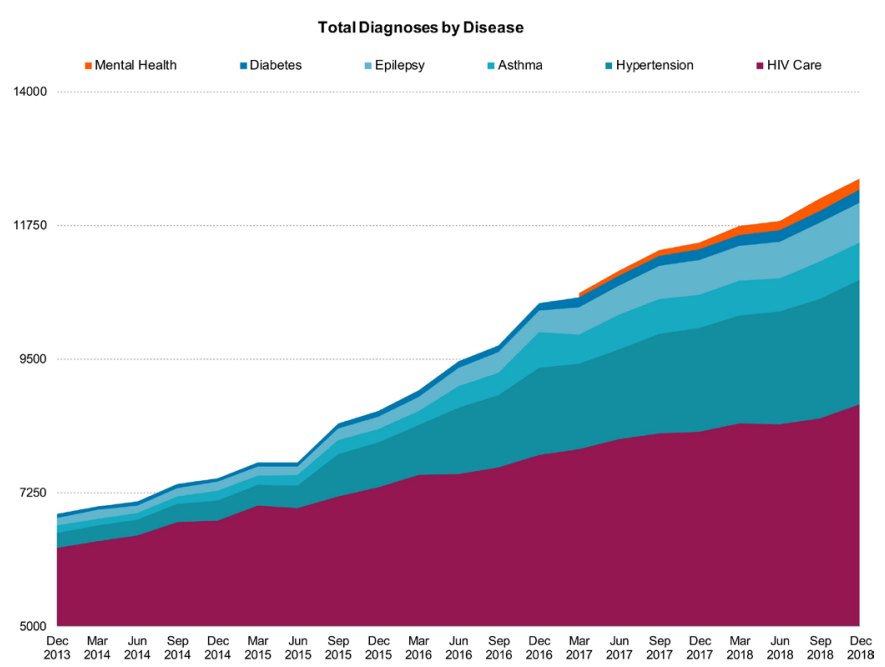

Figure 2 Cumulative enrolments in IC3 over time, by diagnosis. IC3, Integrated Chronic Care Clinic.

in tandem by the $\mathrm{MOH}$ and $\mathrm{PIH}$, and routine updates were given to the DEC. Patients were involved informally through discussions on clinic design, and formally through patient satisfaction surveys (unpublished). The design of the intervention was meant to address the burden of disease in Neno District, and patients with any chronic condition were eligible for enrolment into the clinic.

\section{RESULTS}

Between 2015 and 2017, 6233 patients were enrolled in IC3. These new enrolments included 2990 diagnoses of a chronic NCD and 3334 diagnoses of HIV. As of the end of 2018, these new enrolments made up 56\% of all active patients in the programme, with the remaining $44 \%$ being enrolled before or after the study period. Overall in IC3, 7.6\% of patients with an NCD in care had HIV, and $11.0 \%$ of patients with an NCD in care between the ages of 15 and 49 years had HIV. Among all of the newly enrolled patients with an NCD in this cohort, $2.3 \%$ had HIV and $8 \%$ of clients with an NCD had two or more NCDs. Of these patients, $10 \%(\mathrm{~N}=624)$ were under 15 years, including $13 \%$ of patients with an NCD $(\mathrm{N}=379)$ and $7 \%$ of patients with HIV $(\mathrm{N}=232)$. Figure 1 shows a map of Neno with NCD enrolment limited to the 2 hospitals in 2014 and expanded to all 14 facilities in 2018.
Figure 2 shows overall enrolment for HIV and NCDs between December 2013 and December 2018 with an uptick in NCD enrolments starting in mid-2015 with the decentralisation of NCD care through IC3 as well as community-screening events across the district. After IC3 opened, HIV enrolments remained steady, while there was an increase in NCD enrolment.

Overall enrolment and outcomes are shown in table 1 by diagnosis. Of the $2990 \mathrm{NCD}$ total diagnoses, the most common diagnoses were hypertension $(\mathrm{N}=1693)$, asthma $(\mathrm{N}=668)$ and epilepsy $(\mathrm{N}=486)$. Overall, $25.5 \%$ of patients with $\mathrm{NCD}$ defaulted $(\mathrm{N}=763)$ and $1.4 \%$ died $(\mathrm{N}=41)$. This is compared with defaulting in $8.4 \%$ and deaths in $4.0 \%$ of patients with HIV. (table 1). The default rate among specific NCDs is highest in asthma at $38.1 \%$, followed by mental illness and epilepsy in $24.8 \%$ and $23.0 \%$ of patients, respectively. One-year retention and survival was $72 \%$ in patients with NCD and $85 \%$ in patients with HIV, with a range among specific NCDs from $60 \%$ in patients with asthma to $78 \%$ in patients with hypertension or diabetes (table 1 ).

Table 2 shows clinical characteristics of patients at their enrolment for all patients enrolled during the study period who had at least two visits to clinic. On average, patients with NCD were 46 years old and patients with HIV were 32 years old. Patients with epilepsy, mental illness and asthma tended to be younger with average ages of 24, 30 and 32 years, respectively. Gender also varied across NCD diagnoses, with $67.3 \%$ of the cohort with NCD being women, ranging from $45.9 \%$ of patients with mental illness and $75.2 \%$ of patients with hypertension. Dual-diagnosis patients included patients with NCD over the age of 15 years with HIV, making up $2.6 \%$ of the cohort, while $2.2 \%$ of patients with HIV over the age of 15 years were diagnosed with an NCD.

Clinical outcomes were measured at 1-year postenrolment for all patients enrolled in IC3 over the 3-year period who had more than one visit to clinic (table 3 ). Most clinical measurements showed statistically significant improvement for the cohort on average, including blood pressure, asthma severity, blood sugar and the number of seizures occurring in a month.

In patients with hypertension, at 1-year post-enrolment, less than 5\% remained with blood pressures in the stage III range of SBP >180 and/or DBP $>110 \mathrm{~mm} \mathrm{Hg}$, and

Table 1 IC3 enrolment, retention and survival by diagnosis

\begin{tabular}{|c|c|c|c|c|c|c|c|}
\hline & $\begin{array}{l}\text { All patients with } \\
\text { NCD }\end{array}$ & Hypertension & Asthma & Epilepsy & Diabetes & $\begin{array}{l}\text { Mental } \\
\text { illness }\end{array}$ & HIV \\
\hline Total patients Enrolled & 2990 & 1693 & 668 & 486 & 149 & 109 & 3334 \\
\hline Patients died & $1.4 \%(41)$ & $1.3 \%(22)$ & $1.0 \%(7)$ & $1.2 \%(6)$ & $2.7 \%(4)$ & $1.8 \%(2)$ & $4.0 \%(133)$ \\
\hline $\begin{array}{l}1 \text {-year retention and } \\
\text { survival rate }\end{array}$ & $72 \%$ & $78 \%$ & $60 \%$ & $75 \%$ & $78 \%$ & $72 \%$ & $85 \%$ \\
\hline
\end{tabular}

IC3, Integrated Chronic Care Clinic; NCD, non-communicable disease. 
Table 2 Characteristics at enrolment

\begin{tabular}{|c|c|c|c|c|c|c|c|}
\hline & $\begin{array}{l}\text { All patients } \\
\text { with NCD }\end{array}$ & Hypertension & Asthma & Epilepsy & Diabetes & $\begin{array}{l}\text { Mental } \\
\text { illness }\end{array}$ & HIV \\
\hline $\mathrm{N}$ & 2990 & 1693 & 668 & 486 & 149 & 109 & 3334 \\
\hline Female & $67.3 \%$ & $75.2 \%$ & $64.4 \%$ & $50.0 \%$ & $64.4 \%$ & $45.9 \%$ & $59.7 \%$ \\
\hline $\begin{array}{l}\text { Patients with NCD }>15 \text { years } \\
\text { with HIV }\end{array}$ & $2.6 \%(68)$ & $2.5 \%(42)$ & $3.0 \%(14)$ & $2.2 \%(7)$ & $3.4 \%(5)$ & $3.4 \%(3)$ & \\
\hline
\end{tabular}

*SDs are shown in parentheses for averages.

NCD, non-communicable disease.

$53.6 \%$ had controlled blood pressure defined as $<140 / 90$ $\mathrm{mm} \mathrm{Hg}$. Of patients with hypertension, $84 \%$ had their blood pressure checked at their last visit. Supporting the strategy to enrol sicker patients with higher blood pressures first, $70 \%$ of the cohort with hypertension was on two or more medications.

Among patients with asthma, $87 \%$ had a recorded severity at their last visit, and those reporting their severity as moderate or severe persistent made up $21.8 \%$ of the patients at enrolment and $13.7 \%$ of the patients at their 1-year visit. A steroid inhaler was prescribed in $86 \%$ of patients with asthma.

Similarly, patients with epilepsy reported fewer seizures overall after 1 year of treatment, from an average of 2.4 seizures per quarter at enrolment to 1.5 per quarter at 1-year follow-up. In addition, almost $40 \%$ of patients had not had any seizures since their last visit. Most patients were only on one medication; $14 \%$ of patients with epilepsy were on two or more medications.

Fingerstick glucose results for diabetes were combined among the fasting and random results due to the fact that data indicating type of test were often missing. This average improved from 230 to $179 \mathrm{mg} / \mathrm{dL}$ at 1 year, with $73 \%$ of patients having a fingerstick at their 1-year visit under $200 \mathrm{mg} / \mathrm{dL}$. Almost $70 \%$ of patients with diabetes had their blood pressure controlled at follow-up $(81 \%$ of patients with diabetes had their blood pressure checked at their last visit). Patients on insulin made up $18 \%$ of the cohort with diabetes.

The cohort with HIV in this study maintained excellent outcomes as had been previously demonstrated. ${ }^{53}$ For patients with HIV enrolled during the 3-year study period, $80 \%$ had viral load results recorded after 12 months of antiretroviral therapy, and $85 \%$ of them had an undetectable viral load, with $94 \%$ below Malawi's threshold of 1000 copies/mL.

\section{DISCUSSION}

The IC3 model is a bold attempt at rapid NCD care decentralisation in a rural district. Here we present a descriptive cohort of an integrated service delivery model treating patients with HIV and/or one or more
NCDs concurrently, decentralised from 2 hospitals to 12 primary care facilities. Our study shows an increase in the number of patients with NCD accessing services since the inception of the IC3 and demonstrates favourable 1-year clinical outcomes and retention in care for patients with NCDs while maintaining the excellent clinical outcomes and the rate of enrolment for patients with HIV.

To our knowledge this is the first description of clinical outcomes for comprehensive NCD care in Malawi that is fully decentralised to the primary care level. It is also the sole example in Malawi of fully integrated HIVNCD care for all patients with chronic illness, regardless of their HIV status. Furthermore, very few examples of such a model exist in the global literature to date. In Kruk et al's description of redesigning primary care to address chronic NCDs, four elements are suggested as essential for addressing NCDs through primary care models: 'integration of services, innovative service delivery, a focus on patients and communities, and adoption of new technologies for communication'. The IC3 model encompasses the first three of these, and a future implementation of point-of-care medical record data entry is planned. ${ }^{27} 45$

Increasing enrolment following care integration and decentralisation indicates success in implementation: 6233 new patients were enrolled during the 3-year period of the study, $48 \%$ of them with chronic NCDs. Given the long history of the HIV programme in Neno, the HIV program was much closer to total case finding-that is, finding all of the anticipated patients with HIV living in the district-than for NCDs. ${ }^{41}$ At the end of the study period, $8.1 \%$ of all patients with NCD, and $11.0 \%$ of patients with NCD aged 15-49 years ever enrolled in IC3 were also being treated for HIV. These percentages are higher than the entirety of the study cohort because as screening improved, more NCDs were found and diagnosed in existing patients with HIV who were enrolled before the start of the study period.

The distribution of diagnoses in Neno District is partly reflective of the prevalence of conditions and partly reflective of what conditions are actively screened for in community programmes and in clinics. Of the NCDs, hypertension is, unsurprisingly, the most common, despite 
Table 3 One-year clinical outcomes

\begin{tabular}{|c|c|c|c|}
\hline \multicolumn{3}{|l|}{ Hypertension } & \multirow{2}{*}{$\begin{array}{l}\mathrm{P} \text { value } \neq \\
\mathrm{N}=1075\end{array}$} \\
\hline & Enrolment & After 1 year & \\
\hline Average blood pressure & $\begin{array}{l}\text { 157/94 (SD†: systolic 28, diastolic } \\
\text { 18) }\end{array}$ & $\begin{array}{l}136^{\star} / 83^{\star}(\mathrm{SD}: \text { systolic } 21 \\
\text { diastolic } 13)\end{array}$ & $\begin{array}{l}\text { Systolic: }<0.0001 \\
\text { Diastolic: }<0.0001\end{array}$ \\
\hline $\begin{array}{l}\text { Stage III hypertension BP } \\
>180 / 110\end{array}$ & $26.2 \%(n=322)$ & $4.7 \% *(n=50)$ & $<0.0001$ \\
\hline $\begin{array}{l}\text { Controlled hypertension BP } \\
<140 / 90\end{array}$ & & $53.6 \%(n=575)$ & \\
\hline \multirow[t]{2}{*}{ Asthma } & & & P value $\neq$ \\
\hline & Enrolment & After 1 year & $N=331$ \\
\hline $\begin{array}{l}\text { Asthma severity: moderate or } \\
\text { severe persistent }\end{array}$ & $21.8 \%(n=72)$ & $12.6 \% *(n=42)$ & 0.0007 \\
\hline \multirow[t]{2}{*}{ Epilepsy } & & & $P$ value $\neq$ \\
\hline & Enrolment & After 1 year & $\mathrm{N}=\mathbf{2 0 7}$ \\
\hline $\begin{array}{l}\text { Average number of seizures in } \\
\text { the past } 3 \text { months }\end{array}$ & 2.4 & $1.5^{\star}$ & 0.0003 \\
\hline Zero seizures since last visit & & $38.2 \%(n=79)$ & \\
\hline \multirow[t]{2}{*}{ Diabetes } & & & P value $\neq$ \\
\hline & Enrolment & After 1 year & $\mathrm{N}=52$ \\
\hline Average fingerstick glucose§ & 230 (SD 155) & $179 *(S D 90)$ & 0.0124 \\
\hline Fingerstick glucose $<200$ & & $73 \%(n=38)$ & \\
\hline Average blood pressure & $\begin{array}{l}\text { 143/89 (SD: systolic 25, diastolic } \\
\text { 14) }\end{array}$ & $\begin{array}{l}\text { 130*/84* (SD: systolic } 22 \text {, } \\
\text { diastolic } 11)\end{array}$ & $\begin{array}{l}\text { Systolic: }<0.0001 \\
\text { Diastolic: }<0.0001\end{array}$ \\
\hline $\mathrm{BP}<140 / 90$ & & $69 \%(n=36)$ & \\
\hline \multirow[t]{2}{*}{ HIV } & & & P value $\neq$ \\
\hline & & After 1 year $(\mathrm{N}=2250)$ & \\
\hline $\begin{array}{l}\text { Patients with a recorded viral } \\
\text { load }\end{array}$ & & $80 \%(n=1807)$ & \\
\hline Patients with a viral load $<1000$ & & $94 \%(n=1692)$ & \\
\hline $\begin{array}{l}\text { Patients with an undetectable } \\
\text { viral load }\end{array}$ & & $85 \%(n=1527)$ & \\
\hline
\end{tabular}

Greyed boxes indicate analysis that was not included as part of the study because these measurements were not relevant at the baseline clinic visit.

*Statistically significant at $p<0.05$ level.

†SD showed for all averages.

†Paired one-sided t-test for normal continuous values, Wilcoxon signed rank test for non-normal continuous variables (number of seizures for patients with epilepsy) and McNemar's $\mathrm{X}^{2}$ for proportions.

$\S$ Combines random, fasting and unlabelled.

BP, blood pressure.

using a high threshold for enrolment. Neno District has several, unique screening programmes for hypertension and diabetes, including integrated community-screening events. $^{9}{ }^{49}$ Notably, as Malawi works toward Universal Health Coverage, there is still a large number of patients who need diagnosis and treatment for common NCDs in Neno. For example, the estimated adult hypertension prevalence of $15 \%$ suggests there are approximately 12 000 adults with hypertension in Neno. This means that at the time of this study the clinic was only reaching $18 \%$ of expected patients, with a focus on those with the most severe hypertension. Similar rationale indicates that diabetes coverage thus far is $13 \% .^{9}$
The next most common NCDs were the symptomatic conditions of asthma and epilepsy. Indoor cooking with solid biomass fuel is the mainstay in this rural impoverished district, likely contributing to asthma cases, and epilepsy risk factors of childhood cerebral malaria or meningitis, birth asphyxia and head trauma are abundant in this setting. ${ }^{545}$

The conditions treated at IC3 are only a component of the chronic NCD picture in Malawi: NCDs comprise a family of over 200 conditions, that range from less prevalent but often more severe to those affecting large populations of people. ${ }^{8}$ This broad burden of NCDs in Malawi is a critical factor in scale up: while traditionally 
NCD programmes focus on 'the big four', that is, cardiovascular disease, diabetes, chronic respiratory disease and cancer, these conditions account for just $39 \%$ of the NCD DALYs in Malawi. ${ }^{86}$ Thus, we expect the range of diagnoses in this clinic to diversify over time to reach even more patients with chronic conditions. Additionally, the Neno cohort is primarily adults, although the NCD cohort has $13 \%$ under age 15 years. As the chronic care system expands to include this wider range of diagnoses, we anticipate this proportion may increase to include conditions that tend to affect younger people such as type 1 diabetes, sickle cell disease and nephrotic syndrome. There is discussion whether such a chronic care platform could include support for congenital conditions and disability as well, which would nudge the cohort toward younger ages.

Enrolment of some NCD diagnoses favoured women, such as hypertension and diabetes, which has been seen in previous studies. ${ }^{9}$ This may be related to increased interaction with the health system and thus increased opportunities for screening, through pregnancy care for example. ${ }^{57}$ For some NCD diagnoses that tend to be more overtly symptomatic, such as mental illness and epilepsy, the gender distribution was fairly equal.

Previous research has shown that distance to clinic is a factor for missed visits and default for patients with chronic illness, a barrier that decentralisation to all primary care clinics was designed to address. ${ }^{15} 58$ This cohort did have a high proportion of patients with a visit in the preceding 3 months, a common way to longitudinally follow retention in HIV care in Malawi. Prior to IC3 roll out in 2014, patient default often exceeded $50 \%$ in Neno. ${ }^{59}$ One hypothesis is that simply decentralising care to be available closer to the patient was a large factor in this observed trend.

One-year retention in the cohort was also favourable, remaining high and stable over time for patients with HIV at $85 \%$. This is encouraging as it is similar to rates of HIV retention prior to integration, suggesting that the addition of NCD care to HIV clinics does not compromise HIV outcomes. NCD default was higher than HIV in this cohort, likely due to active default tracking for all clients with HIV in Neno since 2007 by CHWs and the clinical team, whereas this started for patients with chronic NCDs much later, in mid-2017. This also likely means that certainty of outcomes such as death are higher for patients with HIV: we see a slightly higher rate of deaths among the patients with HIV, but it may be that some of the patients with NCD labelled as default had in fact died and follow-up systems were not able to ascertain this information. Despite this, retention rates for NCDs were quite favourable. One-year retention for hypertension, diabetes and epilepsy was in the range of $75 \%-80 \%$, which are excellent results compared with the retention in care literature for chronic NCDs which can be as low as $25 \%$ and some interventions increasing retention to $60 \%-70 \%$. $^{150-62}$

Interestingly, retention in care for asthma was the lowest at $60 \%$. There are a few possibilities that may account for this result. One is that many of these patients did not actually have true asthma, and that the diagnosis was triggered by an acute illness and thereafter improved, or that asthma is occurring more seasonally, so when patients stabilise they drop out of care. A second possibility is that these patients did not experience improved symptoms and thus dropped out of care. Or the opposite could be true: that patients did in fact improve and thus stopped seeing the need for attending clinic when they were feeling better. This could relate to a need for better counselling and teaching for inhaler technique, better control of triggers and additional education around disease chronicity.

Clinical outcomes overall were also favourable, with clinical measures generally improving in the cohort, and though there are some limitations in the observational data, it is encouraging for the provision of primary NCD care in Malawi. However, the limitations to access to primary care for NCDs are real, with significant human resource and drug shortages. ${ }^{81}$ While this programme leveraged many existing resources already in the system through the HIV programme, there was a need for additional staff. The IC3 model is heavily supported by the non-governmental organisation partner, PIH, including for resources for some staff as well as purchasing of a significant quantity of the NCD medications and other commodities. Both of these considerations are critical to address in thinking about the potential for scale for the IC3 model. ${ }^{45}$

There are many lessons learnt in the scale up of the IC3 model to all facilities in Neno. Key considerations for implementers to consider are highlighted in our earlier work and include: (1) a high degree of attention to how patients flow through the clinic; (2) what tasks are shared between different cadres of workers; 3) early and often attention to data management; (4) active strengthening of supply chain needs; (5) how to maintain confidentiality for patients' diagnoses and (6) using higher NCD screening thresholds to avoid overwhelming clinic at the start and ensuring care for the sickest patients. Additionally, critical lessons are in clear leadership in the clinic, identification of where efficiency can be maximised, and an approach using continuous quality improvement. ${ }^{45}$ During the early years of implementation, a critical focus has been training and longitudinal mentorship of clinical and other technical staff. An important staffing intervention was to consistently have the same clinical staff assigned to the clinic, so that long-term investment in clinical teaching and mentorship could be focused on a smaller group of clinicians and nurses. In addition, this approach has revealed that, given the high volume of patients seen in this clinic, it is most suited to patients where diagnosis and management is straightforward, consistent with the WHO Package of Essential Noncommunicable Disease Interventions (PEN) guidelines. ${ }^{63}$ Our experience suggests that patients who need more complex care for more severe disease for diagnoses such as insulin-dependent diabetes, advanced heart disease, kidney or liver failure, or severe rheumatic heart disease, may be better served in an additional level of clinic. Currently, the $\mathrm{MOH}$ in Malawi is exploring the role of district hospitals to treat these conditions, through a model called PEN Plus. ${ }^{64}$ 


\section{Limitations}

There are several limitations to this work. It is an observational cohort using routinely collected clinical data, which limits our ability to evaluate impact based on certain components of the intervention and to know outcomes for patients who default. There are also some limitations in our data. For example, in patients with diabetes, we combined fasting and random fingerstick in the results as it often was not clear in the paper records which state applied. Though the clinic started measuring haemoglobin A1C for patients with diabetes, there were not enough results available during this time period for inclusion. In addition, we were not able to include a reliable clinical outcome indicator for our patients with severe mental illness due to limited data and a small cohort at the time of this study. One of the additional weaknesses of this analysis is that there are some missing data for our disease-control variables (blood pressure, number of seizures, asthma severity and blood glucose) at the 1-year mark. This reflects many operational issues including suboptimal documentation by clinical providers, lack of measurement overall and data entry errors, but we do not have reason to believe that missing data are associated with individual characteristics in our cohort. We are currently working on decreasing missing data in our documentation and aim to follow up with more complete data in future analyses.

\section{CONCLUSION}

This descriptive cohort displays good clinical outcomes and retention in care for patients enrolled in longitudinal primary care for chronic conditions including both HIV and NCDs in rural Malawi. This suggests that integration of HIV and NCD care at primary care clinics may be feasible and effective. Additional work is needed on cost, patient satisfaction, quality of care and possibly integration of other chronic services such as palliative care.

Acknowledgements There are a large number of people and teams who worked hard to make this work possible. Specifically, the authors would like to acknowledge the leadership of Neno's District Health Management Team, the NCD Unit at the National Ministry of Health in Lilongwe, and all of the hardworking IC3 team members. We are also grateful to the support in fundraising and data systems supported by Partners In Health. Finally, we would like to express our appreciation and gratitude to the patients and community in Neno who provided key feedback and support as the team was striving to integrate services and improve quality and systems.

Contributors EBW, CK and NK conceptualised the study. EBW, CK, NK, ELD, LN, LD, $\mathrm{BM}, \mathrm{GG}, \mathrm{EPLN}, \mathrm{GCT}$, LK and EC designed and implemented the program and data systems, and oversaw data collection and interpretation. ELD, LK, CK, NK and EBW designed the data collection system. EBW, AS, NFP, CK and NK contributed to the analysis plan. EBW drafted the manuscript. AS and NFP led the analysis, and ELD supported the analysis. GB, CK, EBW, NK, BM, EPLN and LN provided contextual information for framing of the manuscript background and importance. All authors were involved in the design and execution of the clinic and oversaw the clinical work. Each author provided revisions and comments to the manuscript.

Funding The authors have not declared a specific grant for this research from any funding agency in the public, commercial or not-for-profit sectors.

Map disclaimer The depiction of boundaries on this map does not imply the expression of any opinion whatsoever on the part of BMJ (or any member of its group) concerning the legal status of any country, territory, jurisdiction or area or of its authorities. This map is provided without any warranty of any kind, either express or implied.
Competing interests None declared.

Patient consent for publication Not required.

Ethics approval All data for this study were routinely collected and de-identified clinical data, and no patient was enrolled in a study outside of routine care. Ethical approval was received by the Malawi National Health Sciences Research Committee (NHSRC) and Partners Healthcare Institutional Review Board at Brigham and Women's Hospital in Boston, Massachusetts, USA.

Provenance and peer review Not commissioned; externally peer reviewed.

Data availability statement No data are available. No additional data available, but data questions may be directed to the lead author at ewroe@pih.org.

Open access This is an open access article distributed in accordance with the Creative Commons Attribution Non Commercial (CC BY-NC 4.0) license, which permits others to distribute, remix, adapt, build upon this work non-commercially, and license their derivative works on different terms, provided the original work is properly cited, appropriate credit is given, any changes made indicated, and the use is non-commercial. See: http://creativecommons.org/licenses/by-nc/4.0/.

ORCID iD

Emily B Wroe http://orcid.org/0000-0002-9152-9553

\section{REFERENCES}

1 World Health Organization. Universal health coverage factsheet. Available: https://www.who.int/news-room/fact-sheets/detail/ universal-health-coverage-(uhc)

2 Lacroix P, Houehanou C, Preux PM, et al. Ncd risk factors in Malawi: population characteristics matter. Lancet Diabetes Endocrinol 2018;6:163-4.

3 Barr AL, Young EH, Smeeth L, Young AL, Smeeth EH, et al. The need for an integrated approach for chronic disease research and care in Africa. Glob Health Epidemiol Genom 2016;1:e19.

4 United Nations General Assembly. 2011 high level meeting on prevention and control of non-communicable diseases, 2011. Available: http://www.un.org/en/ga/ncdmeeting2011/

5 Palma AM, Rabkin M, Nuwagaba-Biribonwoha H, et al. Can the success of HIV scale-up advance the global chronic ncd agenda? Glob Heart 2016;11:403-8.

6 Institute for Healthcare Metrics and Evaluation (IHME). Global burden of disease. Seattle WA: IHME. University of Washington, 2016.

7 Malawi Ministry of Health. Resource mapping, round 4, 2015.

8 Malawi Ministry of Health, Malawi NCDI Poverty Commission. Malawi national NCDI poverty commission report, 2018.

9 Price AJ, Crampin AC, Amberbir A, et al. Prevalence of obesity, hypertension, and diabetes, and cascade of care in sub-Saharan Africa: a cross-sectional, population-based study in rural and urban Malawi. Lancet Diabetes Endocrinol 2018;6:208-22.

10 Msyamboza KP, Ngwira B, Dzowela T, et al. The burden of selected chronic non-communicable diseases and their risk factors in Malawi: nationwide steps survey. PLoS One 2011;6:e20316-11.

11 Udedi M, Swartz L, Stewart RC, et al. Health service utilization by patients with common mental disorder identified by the selfreporting questionnaire in a primary care setting in Zomba, Malawi: a descriptive study. Int J Soc Psychiatry 2014;60:454-61.

12 Malawi Ministry of Health. Service provision assessment (SPA). Lilongwe, Malawi, 2012.

13 World Bank. World bank open data, 2017.

14 Chikowe I, Mwapasa V, Kengne AP. Analysis of rural health centres preparedness for the management of diabetic patients in Malawi. BMC Res Notes 2018;11:267.

15 Musicha C, Crampin AC, Kayuni N, et al. Accessing clinical services and retention in care following screening for hypertension and diabetes among Malawian adults: an urban/rural comparison. $J$ Hypertens 2016;34:2172-9.

16 Wood R, Viljoen V, Van Der Merwe L, et al. Quality of care for patients with non-communicable diseases in the Dedza district, Malawi. Afr J Prim Health Care Fam Med 2015;7. doi:10.4102/phcfm.v7i1.838. [Epub ahead of print: 15 Jun 2015].

17 Harries AD, Makombe SD, Libamba E, et al. Why did the scale-up of HIV treatment work? A case example from Malawi. J Acquir Immune Defic Syndr 2011;57:S64-7.

18 Malawi Ministry of Health. Health sector strategic plan II (2017-2022), 2017.

19 Ministry of Health, Government of the Republic of Malawi. Malawi population-based HIV impact assessment (MPHIA) 2015-2016, 2016. 
20 Kieffer MP, Mattingly M, Giphart A, et al. Lessons learned from early implementation of option B+: the Elizabeth Glaser pediatric AIDS Foundation experience in 11 African countries. J Acquir Immune Defic Syndr 2014;67:S188-94.

21 Price AJ, Kayange M, Zaba B, et al. Uptake of prevention of motherto-child-transmission using option $\mathrm{B}+$ in northern rural Malawi: a retrospective cohort study. Sex Transm Infect 2014;90:309-14.

22 Tymejczyk O, Brazier E, Yiannoutsos CT, et al. Changes in rapid HIV treatment initiation after national "treat all" policy adoption in 6 subSaharan African countries: Regression discontinuity analysis. PLoS Med 2019;16:e1002822.

23 Gupta N, Bukhman G. Leveraging the lessons learned from HIV/ AIDS for coordinated chronic care delivery in resource-poor settings. Healthc 2015;3:215-20.

24 Rabkin M, El-Sadr WM. Why reinvent the wheel? Leveraging the lessons of HIV scale-up to confront non-communicable diseases. Glob Public Health 2011;6:247-56.

25 Haldane V, Legido-Quigley H, Chuah FLH, et al. Integrating cardiovascular diseases, hypertension, and diabetes with HIV services: a systematic review. AIDS Care 2018;30:103-15.

26 Piot P, Caldwell A, Lamptey P, et al. Addressing the growing burden of non-communicable disease by Leveraging lessons from infectious disease management. J Glob Health 2016;6, :010304.

27 Kruk ME, Nigenda G, Knaul FM. Redesigning primary care to tackle the global epidemic of noncommunicable disease. Am J Public Health 2015;105:431-7.

28 Crabtree-Ramírez B, Del Río C, Grinsztejn B, et al. Hiv and noncommunicable diseases (NCDS) in Latin America: a call for an integrated and comprehensive response. J Acquir Immune Defic Syndr 2014;67:S96-8.

29 Duffy M, Ojikutu B, Andrian S, et al. Non-communicable diseases and HIV care and treatment: models of integrated service delivery. Trop Med Int Health 2017;22:926-37.

30 Njuguna B, Vorkoper S, Patel P, et al. Models of integration of HIV and noncommunicable disease care in sub-Saharan Africa: lessons learned and evidence gaps. AIDS 2018;32:S33-42.

31 Pfaff $\mathrm{C}$, Singano V, Akello $\mathrm{H}$, et al. Early experiences integrating hypertension and diabetes screening and treatment in a human immunodeficiency virus clinic in Malawi. Int Health 2018;10:495-501.

32 Rabkin M, Nishtar S. Scaling up chronic care systems: Leveraging HIV programs to support noncommunicable disease services. $J$ Acquir Immune Defic Syndr 2011:57:S87-90.

33 Sigfrid L, Murphy G, Haldane V, et al. Integrating cervical cancer with HIV healthcare services: a systematic review. PLoS One 2017;12, :e0181156.

34 Legido-Quigley $\mathrm{H}$, Montgomery CM, Khan P, et al. Integrating tuberculosis and HIV services in low- and middle-income countries: a systematic review. Trop Med Int Health 2013;18:199-211.

35 Pfeiffer J, Montoya P, Baptista AJ, et al. Integration of HIV/AIDS services into African primary health care: lessons learned for health system strengthening in Mozambique - a case study. J Int AIDS Soc 2010;13:3.

36 Washington S, Owuor K, Turan JM, et al. Implementation and operational research: effect of integration of HIV care and treatment into antenatal care clinics on mother-to-child HIV transmission and maternal outcomes in Nyanza, Kenya: results from the SHAIP cluster randomized controlled trial. J Acquir Immune Defic Syndr 2015;69:e164-71.

37 Hyle EP, Naidoo K, Su AE, et al. Hiv, tuberculosis, and noncommunicable diseases: what is known about the costs, effects, and cost-effectiveness of integrated care? J Acquir Immune Defic Syndr 2014;67:S87-95.

38 Topp SM, Chipukuma JM, Chiko MM, et al. Integrating HIV treatment with primary care outpatient services: opportunities and challenges from a scaled-up model in Zambia. Health Policy Plan 2013;28:347-57.

39 Janssens B, Van Damme W, Raleigh B, et al. Offering integrated care for HIV/AIDS, diabetes and hypertension within chronic disease clinics in Cambodia. Bull World Health Organ 2007;85:880-5.

40 Bilinski A, Birru E, Peckarsky M, et al. Distance to care, enrollment and loss to follow-up of HIV patients during decentralization of antiretroviral therapy in Neno district, Malawi: a retrospective cohort study. PLoS One 2017;12:e0185699-13.

41 Wroe EB, Dunbar EL, Kalanga N, et al. Delivering comprehensive HIV services across the HIV care continuum: a comparative analysis of survival and progress towards 90-90-90 in rural Malawi. BMJ Glob Health 2018;3, :e000552.
42 Kwan GF, Bukhman AK, Miller AC, et al. A simplified echocardiographic strategy for heart failure diagnosis and management within an integrated noncommunicable disease clinic at district hospital level for sub-Saharan Africa. JACC Heart Fail 2013;1:230-6.

43 Eberly LA, Rusingiza E, Park PH, et al. 10-year heart failure outcomes from nurse-driven clinics in rural sub-Saharan Africa. J Am Coll Cardiol 2019;73:977-80.

44 Habineza H, Mutumbira C, Hedt-Gauthier BL, et al. Treating persistent asthma in rural Rwanda: characteristics, management and 24-month outcomes. Int J Tuberc Lung Dis 2017;21:1176-82.

45 Wroe EB, Kalanga N, Mailosi B, et al. Leveraging HIV platforms to work toward comprehensive primary care in rural Malawi: the integrated chronic care clinic. Healthc 2015;3:270-6.

46 Kane J, Landes M, Carroll C, et al. A systematic review of primary care models for non-communicable disease interventions in subSaharan Africa. BMC Fam Pract 2017;18:46.

47 Malawi National Statistics Office. 2008 population and housing census: population projections, 2008. Available: http://www. nsomalawi.mw/index.php?option=com_content\&view=article\&id= 106\&ltemid $=6$

48 National Statistical Office (NSO). 2015-2016 Malawi demographic and health survey key findings. Zomba, Malawi, and Rockville, Maryland, USA. NSO and ICF, 2017: 1-20.

49 Partners In Health. Integrated care cascade toolkit, 2017.

50 Kachimanga C, Cundale K, Wroe E, et al. Novel approaches to screening for noncommunicable diseases: lessons from Neno, Malawi. Malawi Med J 2017;29:78-83.

51 Dunbar EL, Wroe EB, Nhlema B, et al. Evaluating the impact of a community health worker programme on non-communicable disease, malnutrition, tuberculosis, family planning and antenatal care in Neno, Malawi: protocol for a stepped-wedge, cluster randomised controlled trial. BMJ Open 2018;8:e019473.

52 StataCorp. Stata statistical software: release 14. College Station, TX: StataCorp LP, 2015.

53 Herce ME, Kalanga N, Wroe EB, et al. Excellent clinical outcomes and retention in care for adults with HIV-associated Kaposi sarcoma treated with systemic chemotherapy and integrated antiretroviral therapy in rural Malawi. J Int AIDS Soc 2015;18:19929-10.

54 Rylance S, Nightingale R, Naunje A, et al. Lung health and exposure to air pollution in Malawian children (CAPS): a cross-sectional study. Thorax 2019;74:1070-7.

55 Ba-Diop A, Marin B, Druet-Cabanac M, et al. Epidemiology, causes, and treatment of epilepsy in sub-Saharan Africa. Lancet Neurol 2014;13:1029-44.

56 Cundale K, Wroe E, Matanje-Mwagomba BL, et al. Reframing noncommunicable diseases and injuries for the poorest Malawians: the Malawi national NCDI poverty Commission. Mal Med J;29:194-7.

57 Yeatman S, Chamberlin S, Dovel K, Dovel, "Women's K. Women's (health) work: a population-based, cross-sectional study of gender differences in time spent seeking health care in Malawi. PLoS One 2018;13, :e0209586.

58 Rachlis B, Naanyu V, Wachira J, et al. Identifying common barriers and facilitators to linkage and retention in chronic disease care in Western Kenya. BMC Public Health 2016;16:1-15.

59 Neno District Open. MRS electronic medical record [internal data], 2019.

60 Sobry A, Kizito W, Van den Bergh R, et al. Caseload, management and treatment outcomes of patients with hypertension and/or diabetes mellitus in a primary health care programme in an informal setting. Trop Med Int Health 2014;19:47-57.

61 Labhardt ND, Balo J-R, Ndam M, et al. Improved retention rates with low-cost interventions in hypertension and diabetes management in a rural African environment of nurse-led care: a cluster-randomised trial. Trop Med Int Heal 2011;16:1276-84.

62 Saito M, Keereevijit A, San TD, et al. Challenges to primary healthcare services in the management of non-communicable diseases in marginalised populations on the Thailand-Myanmar border: a pilot survey. Trop Doct 2018;48:273-7.

63 World Health Organization. Package of essential noncommunicable (pen) disease interventions for primary health care in low-resource settings, 2010.

64 World Health Organization African Region. PEN-plus meeting in Kigal - the management and treatment of non-communicable diseases at primary levels strengthened, 2019. Available: https://www.afro.who. int/news/pen-plus-meeting-kigali-management-and-treatment-noncommunicable-diseases-primary-levels 